\title{
Microscopia de Varredura por Força: uma Ferramenta Poderosa no Estudo de Polímeros.
}

\author{
Paulo S. P. Herrmann, Marcelo A. P. da Silva, Rubens Bernardes Fo, \\ Aldo E. Job, Luiz A. Colnago, Jane E. Frommer e Luiz H.C. Mattoso
}

\begin{abstract}
Resumo: As técnicas de microscopia de varredura por força tem promovido um grande impacto em ciência dos materiais devido a possibilidade de obtenção de imagens em escala que pode chegar no nível atômico. Neste trabalho serão apresentados o princípio básico de funcionamento da microscopia de varredura por força, os vários modos de operação e as forças envolvidas e medidas. O potencial de aplicação destas técnicas no estudo de materiais, e em particular de polímeros, serão discutidos. Uma comparação da microscopia de força atômica com outras técnicas de microscopia será apresentada, assim como exemplos da utilização da técnica de microscopia de força atômica para o estudo de polímeros.
\end{abstract}

Palavras-chave: Microscopia de varredura por força, morfologia, estrutura, polímeros

\section{Introdução}

A microscopia de varredura por força, "scanning force microscopy" SFM é uma das técnicas mais recentes no estudo de polímeros. A alta resolução da imagem obtida, a facilidade na preparação de amostras para análise e a disponibilidade de instrumentos comerciais de alta qualidade fazem desta técnica uma poderosa ferramenta para o estudo de materiais. O campo de aplicação do SFM, hoje em dia, envolve técnicas de medidas de diversos tipos de força, tais como: mecânica (topografia), elétrica e magnética as quais abriram campos para a pesquisa e desenvolvimento que até 15 anos atrás eram inimagináveis.

O microscópio de força atômica "atomic force microscope" - AFM, o primeiro da linha do SFM, abrange aplicações simples, desde o estudo da morfologia de superfície dos polímeros até o exame das características morfológicas, estruturais e moleculares de propriedades em escala nanométrica. Embora os polímeros tenham uma grande importância tecnológica, muito ainda deve ser feito para o melhor conhecimento da sua morfologia e nanoestrutura. É por isso que o aparecimento da técnica de AFM tem causado um impacto tão grande na pesquisa e desenvolvimento de compostos macromoleculares.

O precursor do AFM foi o microscópio de varredura por tunelamento, "scanning tunneling microscope" - STM. A técnica chegou ao conhecimento da comunidade científica em 1982, com a publicação de um artigo, no Physical Review Letters ${ }^{[1]}$. Em 1986 os pesquisadores da IBM, Gerd Binnig e Henrich Roher, inventores desta técnica, foram laureados com o prêmio Nobel de física. No entanto, o

\footnotetext{
Paulo S.P. Herrmann ${ }^{1,2,4}$, Marcelo A. P. Silva ${ }^{3}$, Rubens Bernardes Fo ${ }^{1,2}$, Aldo E. Job ${ }^{3}$, Luiz A. Colnago ${ }^{1,2}$, Jane E. Frommer $^{4}$, Luiz H.C. Mattoso $^{1}$ 1 - Centro Nacional de Pesquisa e Desenvolvimento de Instrumentação Agropecuária, CNPDIA/EMBRAPA, C.P. 741, CEP 13560-970, São Carlos, SP 2 - Instituto de Química de São Carlos, DFQ/IQSC/USP, C.P. 369, CEP 13560-970, São Carlos, SP

3 - Instituto de Física de São Carlos, FCM/IFSC/USP, CP 369,CEP 13560-970 São Carlos, SP

4 - Almaden Research Center, IBM, San Jose, Harry Road 650, 96540, CA, USA
} 
STM ainda apresenta a limitação da necessidade de que a amostra e a agulha sejam semicondutores ou condutores, restringindo o número de materiais na qual a técnica pode ser empregada. Este tipo de problema levou a introdução, em 1986, do microscópio de força atômica ${ }^{[2]}$.

O primeiro AFM para escala comercial, com produção em série, foi apresentado em 1989. Desde então, o número de publicações enfatizando os trabalhos com a técnica tem crescido significativamente, sendo no período de 2,5 anos (1993 a 1996) de cerca de 6000 artigos publicados ${ }^{[3]}$. Segundo dados de uma das três maiores empresas que produzem e comercializam os microscópio de varredura por sonda, "scanning probe microscopy" - SPM, o mercado mundial, potencial para ano o de 1997, é da ordem de US\$ 100 milhões. É importante esclarecer que o microscópio de varredura por sonda é uma família maior que engloba os outros dois tipos de microscópios, o de varredura por tunelamento e o de varredura por força. Em termos de preço unitário o custo de um SPM, está na faixa de US\$30.000-US\$200.000. Esta variação de preço dependerá basicamente da configuração do sistema escolhido em termos de hardware e software e dos acessórios.

Devido a recente comercialização do SPM, vale a pena ressaltar que $75 \%$ das técnicas utilizadas, para obtenção e análise de imagem, foram desenvolvidas nos últimos cinco anos.

\section{Vantagens da Microscopia de Força Atômica}

A microscopia de força atômica (AFM) e outras técnicas que pertencem a família dos microscópios de varredura por sonda (SPM), têm recebido uma grande quantidade de estudos e investimentos nos últimos anos, devido a sua maior resolução e menor custo comparada às microscopias eletrônicas de varredura (SEM) e de transmissão (TEM). Enquanto os melhores microscópios eletrônicos comerciais possibilitam aumentos de no máximo algumas centenas de milhares de vezes, o AFM pode obter imagens com aumento de várias dezenas de milhões de vezes, com a vantagem de ter esta mesma resolução nas 3 dimensões, o que não ocorre com os primeiros. Além disso, a alta energia do feixe de elétrons dos microscópios SEM danificam as amostras poliméricas limitando a operação do equipamento, na prática, para aumentos abaixo de 50.000 vezes para a maioria dos polímeros.

As principais vantagens do AFM, quando comparado ao SEM, para a análise morfológica e estrutural de materiais, em geral, são: maior resolução, imagem em 3 dimensões, não existe necessidade de recobrimento condutivo, não requer métodos específicos de preparação da amostra, permite a quantificação direta da rugosidade da amostra, permite a medida da espessura de filmes ultra-finos sobre substratos, análise por fractal, pode diferenciar fases com diferentes viscoelasticidades, permite a medida de propriedades mecânicas do material analisado em escala nanométrica, análise de amostras imersas em meio líquido e menor custo do que os microscópios eletrônicos.

No caso de polímeros, existem ainda algumas limitações desta técnica, devido justamente ao alto grau de complexidade da estrutura, baixo grau de ordenamento e cristalinidade e menor módulo de elasticidade destes materiais. No entanto, estudos ainda estão sendo feitos para melhor expandir a aplicação do AFM em polímeros nos seguintes aspectos: aumentar a resolução até nível atômico, diminuir a interferência em amostras de baixa dureza, melhorar a análise quantitativa morfológica da amostra e, utilizar novas técnicas de obtenção de imagens, tais como gradiente de força elétrica e potencial de superfície, entre outras.

\section{Princípio de Funcionamento}

O conhecimento do princípio de funcionamento desta nova geração de microscópios é de extrema importância para se escolher a melhor técnica a ser utilizada para se analisar um determinado tipo de material. O principio básico de funcionamento dos microscópios de varredura por força - SFM pode ser visto no diagrama em blocos ilustrado na Figura 1. Neste tipo de microscópios as imagens são geradas através da medida das forças de atração ou repulsão entre a superfície da amostra e uma sonda ou agulha bem fina que varre a amostra. Esta varredura é feita, por intermédio de um sistema piezoelétrico, com deslocamento, nas posições $\mathrm{x}, \mathrm{y}$ e $\mathrm{z}$ com precisão de décimo de Angstron, o que se dá através da variação da tensão aplicada no mesmo. $\mathrm{O}$ deslocamento é controlado por um circuito de realimentação cuja função é manter a força e/ou altura constante. Como as forças envolvidas são da ordem de $10^{-12} \mathrm{~N}$, foi necessário desenvolver um sistema de detecção ultra sensível. A solução prática 


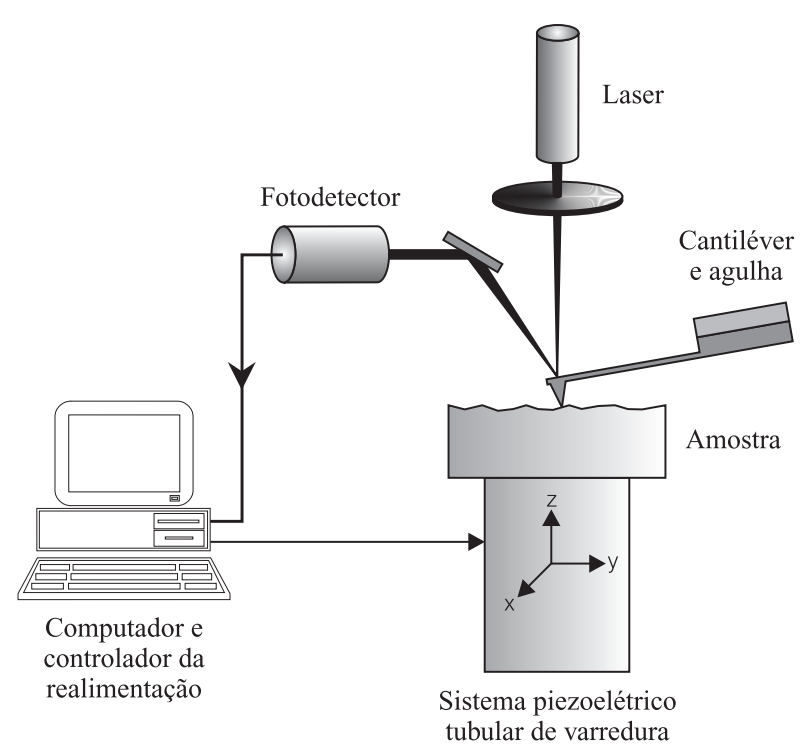

Figura 1. Ilustração do princípio de funcionamento do microscópio de varredura por força - SFM.

encontrada para medir forças desta ordem foi colocar a agulha na ponta de uma haste (cantiléver) com baixa constante de mola. Desta forma, a deflexão no cantiléver causada pela interação da agulha com a amostra pode ser medida. Um sistema ótico, com feixe a laser e um fotodetector, determinam o quanto o cantiléver deflete devido a topografia da amostra. Com os dados da deflexão do cantiléver nos eixos x, y e z, reconstrói-se a imagem por intermédio de software dedicado. No modo contato, a força que o cantiléver exerce sobre a amostra, provocada pelo deslocamento do eixo $z$ do piezo, permite a quantificação de propriedades do material sendo analisado. No entanto, esta força deve ser controlada para que não ocorra danos ao sistema amostra-agulha.

\section{Sistema Básico dos Microscópios de Varredura por Força}

\section{O Cantiléver}

O cantiléver e a agulha são os elementos sensores dos microscópios de varredura por força. A agulha, colocada no final do cantiléver, mapeia a amostra. O cantiléver mede a força de interação entre a amostra e a agulha. Para imagens de topografia normal, a agulha é colocada em contato contínuo ou intermitente com a amostra sendo varrida ou arrastada sobre a sua superfície. O cantiléver é usualmente constituído de

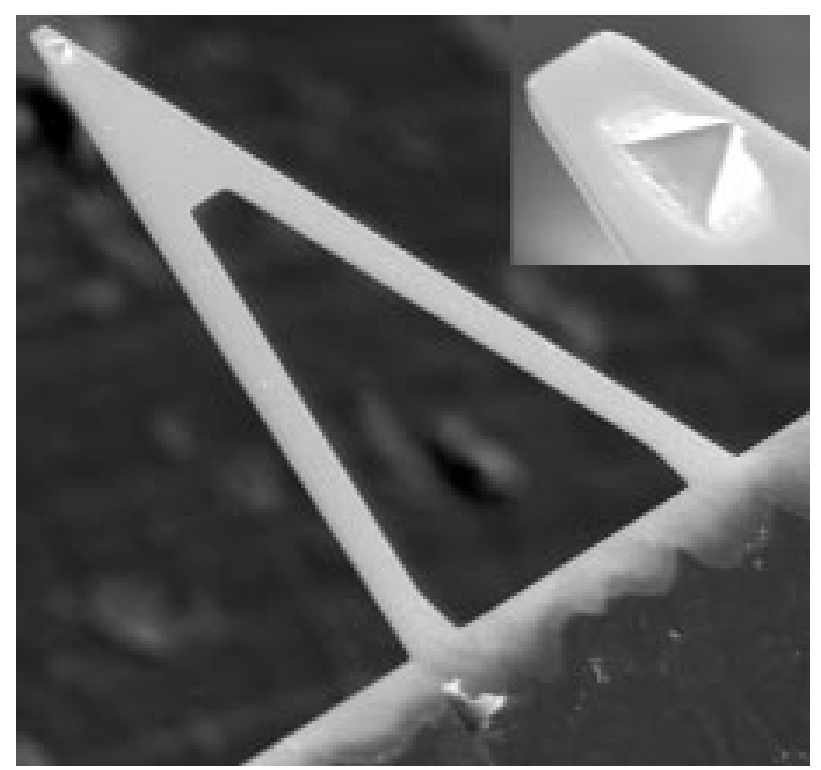

Figura 2. Microscopia eletrônica de varredura de um cantiléver de nitreto de silício com agulha acoplada (em detalhe).

uma ou mais hastes de silício ou nitreto de silício que tem comprimento de 100 a 500 micra e espessura de 0,5 a 5 micra. A agulha possui alguns micra de comprimento, e diâmetro menor que 400 Angstrons.

A Figura 2 mostra o cantiléver e a agulha de nitreto de silício (no detalhe); a imagem foi obtida com microscopia eletrônica de varredura. $O$ cantiléver deve possuir um baixo valor de constante de mola, que seja menor do que a constante de mola efetiva que mantém os átomos da amostra juntos, o que está em geral em torno de $10 \mathrm{~N} / \mathrm{m}$. A constante de mola do cantiléver do AFM é determinada pelas propriedades geométricas (comprimento, largura e espessura) e pelo módulo elástico do material do cantiléver. $\mathrm{Na}$ prática, existem cantilévers comerciais com uma variedade de constantes de mola, desde 0,01 até 100 Newtons/metro, oferecendo uma vasta gama de opções de medida para uma infinidade de materiais.

\section{O Sistema de Varredura}

O sistema de varredura é outro elemento determinante da resolução dos SFM. Este é formado por um sistema de varredura piezoelétrico que gera a movimentação necessária $(\mathrm{x}, \mathrm{y}$ e $\mathrm{z})$ para obtenção de imagens topográficas nas 3 dimensões e medidas de força. O sistema piezoelétrico é um dispositivo que se move em escala nanométrica/micrométrica quando uma voltagem é aplicada entre seus eletrodos. Os sistemas de varredura são usados também para transladar a amostra até o cantiléver ou o 
cantilever até a amostra. Um sistema de varredura bem construído pode gerar movimentos estáveis em escalas de décimos de Angstron. Os sistemas de varredura piezoelétricos para AFM podem transladar em três direções de forma a varrer dimensões desde alguns Angstrons até centenas de micra nos eixos $\mathrm{X}$ e $\mathrm{Y}$ e no eixo vertical $Z$ de décimos de Angstrons a alguns micra.

\section{O Sistema de Detecção do Deslocamento do Cantiléver}

A medida de força e obtenção das imagens por SFM é realizada registrando-se o deslocamento da ponta livre do cantiléver quando esta é atraída ou repelida pela amostra.

O método de detecção que vem sendo utilizado, na maioria dos SFMs comerciais, é o da reflexão do feixe de laser ${ }^{[4]}$. Este sistema mede o deslocamento do cantiléver através da incidência e reflexão de um feixe de laser na ponta livre espelhada livre do cantiléver. A maioria dos equipamentos comerciais utilizam laser com comprimento de onda de $650 \mathrm{~nm}$ e potência de $5 \mathrm{~mW}$. As deflexões do cantiléver causam uma mudança no ângulo de reflexão do feixe de laser, que após refletir em um espelho, é detectado por um fotodiodo de segmento múltiplo. A sensibilidade da medida vertical do SFM depende do comprimento do cantiléver, ou seja, para uma mesma deflexão vertical o cantiléver mais curto produz uma deflexão angular menor do que o cantiléver longo.

\section{Sistema de controle e realimentação}

Nos sistemas comerciais a distância entre a amostra e a sonda é mantida constante (ou oscilando entre valores constantes), através da variação da tensão aplicada no piezoelétrico no eixo Z $\mathrm{Z}$. Como as mudanças no piezoelétrico não são instantâneas, o sistema de realimentação controla o deslocamento no eixo $\mathrm{Z}$ para que ele ocorra da maneira mais fiel possível. As operações de controle e realimentação, assim como a aquisição de dados, construção e processamento das imagens são realizadas por um microcomputador.

\section{Modos de Operação do Microscópio e Forças Envolvidas}

Os microscópios de varredura por força não se limitam a obtenção de imagens, mas são técnicas pode-

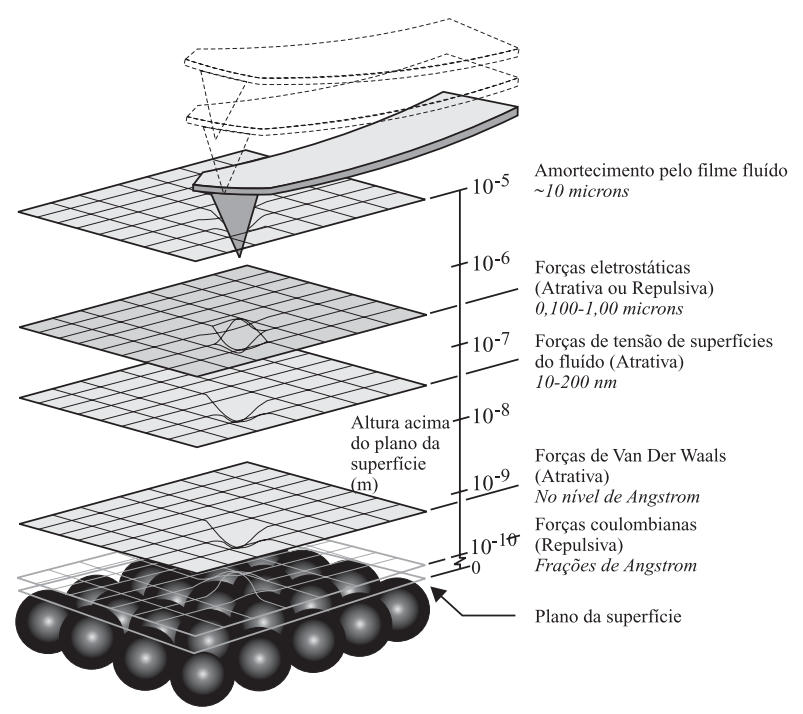

Figura 3. Relação de forças que atuam entre a agulha e amostra em função da distância que as separa (Reprodução com permissão da Digital Instruments $)^{[5]}$.

rosas que permitem a análise de forças e propriedades em escala nanométrica. Portanto, para melhor se explorar o potencial destas técnicas é importante conhecer os chamados modos de operação do microscópio, pois estes determinam o tipo de forças que estarão sendo envolvidas, e desta forma as características possíveis de serem analisadas na amostra em questão.

Vários tipos de forças contribuem para a deflexão de um cantiléver em um AFM. A Figura 3 ilustra de forma simplificada as forças envolvidas, de acordo com a distância que separa a agulha da amostra ${ }^{[5]}$. A curva de força em função da distância é uma outra forma de se analisar esta interação ${ }^{[6,7]}$. Na Figura 4 pode-se observar esta relação, a qual permite avaliar o regime e o modo de trabalho do sistema.

Para dois corpos eletricamente neutros e não magnéticos separados por uma ou várias dezenas de nanômetros, pode-se dizer que as forças de van der Waals (VDW) usualmente dominam a interação entre eles ${ }^{[8]}$. Estas forças são consideradas atrativas. Diminuindo a distância de separação entre os dois corpos, para alguns Angstrons, as forças que irão dominar serão as forças repulsivas, isto se deve principalmente a componente de força coulombiana. Desta forma, a distância agulha-amostra determina o modo de operação do microscópio.

\section{AFM pelo Modo Contato}

O modo contato, ou modo de detecção dc, é o modo mais básico de operação do AFM. Neste caso, a agulha varre a amostra mantendo a menor distância possível, 


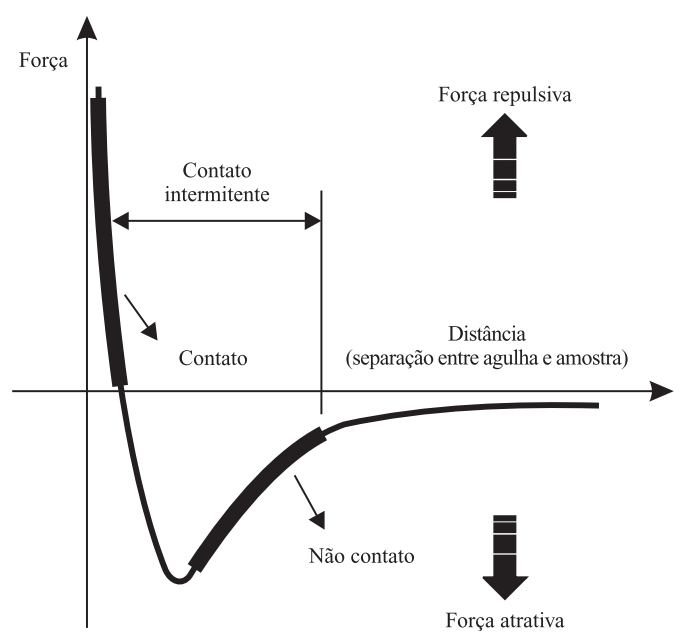

Figura 4. Curva de força pela distância de separação entre a agulha e amostra (Cortesia Park Scientific Instruments) ${ }^{[6]}$.

na faixa das distâncias interatômicas. As forças envolvidas são forças de repulsão, sendo necessário um cuidado grande para que a agulha não danifique a amostra.

A força realizada pela ponta do AFM é calculada multiplicando-se a deflexão do cantiléver pela sua constante de mola, no caso do modo contato. Por exemplo, se um cantiléver com uma constante de mola de 1 Newton/metro é defletida de $1 \mathrm{~nm}$, a força de mola realizada pelo cantiléver é de $1 \mathrm{nN}\left(10^{-9} \mathrm{~N}\right)$.

$$
\mathrm{F}=\mathrm{K} \cdot \mathrm{Z}
$$

onde: F é a força em Newtons (N), Ké a constante de mola $\left(\mathrm{N} . \mathrm{m}^{-1}\right)$ e $\mathrm{Z}$ é o valor da deflexão do cantiléver.

No modo contato a pequena força repulsiva entre a agulha e a amostra é da ordem de $10^{-6}$ à $10^{-9} \mathrm{~N}$. Neste caso, é de fundamental importância um sistema com boa sensibilidade para detectar a deflexão do cantiléver.

\section{AFM pelo Modo Não-contato}

A técnica de não-contato explora outros níveis de interação de força como mostrado pela Figura 3. Este método, conhecido como método de detecção- $a c$, é sensível ao gradiente de força e oferece vantagem significativa quando comparado ao método de detecção$d c$ para medidas de deflexão do cantiléver usado para o estudo das forças de longo alcance. A força total entre a agulha e amostra, no regime de modo não-contato, geralmente está em torno de $10^{-12} \mathrm{~N}^{[9]}$, o que é menor do que no modo contato, minimizando assim o contato físico agulha-amostra e consequentemente a deformação da amostra. O método baseia-se na separação da agulha em relação a amostra em torno de 10 a $100 \mathrm{~nm}$. Somente forças de interação de longo alcance interagirão, no caso, van der Waals, eletrostática e força de dipolo magnético. O método para a medida da interação de força no modo não-contato com AFM é usualmente diferente do modo contato. Ao invés de medir a deflexão do cantiléver quasi-estática, o cantiléver é colocado a vibrar próximo da sua freqüência de ressonância pelo uso de um elemento piezoelétrico ${ }^{[10]}$. Mudanças no valor da freqüência de ressonância ocorrerão devido ao resultado da força de interação entre agulha-superfície. O uso da propriedade da resposta em freqüência do cantiléver faz com que haja uma melhora na relação sinal/ruído.

\section{AFM pelo Modo Contato Intermitente}

O princípio de funcionamento do modo contato intermitente, "quasi non-contact" ou "tapping mode"[5], é similar ao sistema de trabalho do nãocontato, isto é, o cantiléver vibra, por intermédio de um sistema piezoelétrico, próximo a sua freqüência de ressonância. O cantiléver juntamente com a agulha é colocado bem próximo a amostra até que o deslocamento contínuo e controlado do piezoelétrico faça com que a agulha toque levemente a amostra. A agulha oscila com uma amplitude de vibração do cantiléver entre 20 e $100 \mathrm{~nm}$, mas somente "bate" na amostra por um breve período do tempo total de vibração. Durante uma varredura, a oscilação vertical da agulha entra em contato com a amostra por um curtíssimo período de tempo e salta para fora da amostra com uma frequência de 50.000 a 500.000 vezes por segundo.

Esta técnica vem sendo aplicada com bons resultados em alguns tipos de amostras consideradas macias, como por exemplo polímeros e materiais biológicos, pois ao contrário do modo contato, o modo contato intermitente elimina basicamente a influência da força lateral que pode deformar ou até danificar a amostra. Quando comparado com o modo não-contato a mesma torna-se mais efetiva por realizar imagens de grandes áreas que podem incluir maiores variações na topografia da amostra. Alguns aparelhos permitem explorar a deteç̧ão de fase, e devido a sensibilidade da técnica é possível extrair novas informações da imagem, como por exemplo diferenças entre módulos de elasticidade das fases presentes.

\section{Outros Modos de Operação}

No modo de força lateral de operação da microscopia SFM a agulha é varrida na direção per- 
pendicular ao seu comprimento, ou seja, lateralmente ao eixo de varredura mais rápida. A torsão ou rotação do cantiléver irá aumentar ou diminuir dependendo das características de fricção da superfície, sendo que um aumento da fricção irá aumentar a torção resultante ${ }^{[11-13]}$. Uma vez que neste caso o detetor do laser tem quatro quadrantes ele pode medir simultaneamente os dados de topografia e de força lateral. Estes dados podem ser processados separadamente e visualizados simultaneamente.

Uma outra utilização do modo de força lateral é o modo de força química, onde a agulha é modificada com uma espécie química específica desejada e varrida sobre a amostra para detectar diferenças de adesão entre a amostra e a espécie química colocada na agulha.

No modo contato normal o sistema mantém uma força constante sobre a amostra e consequentemente uma deflexão constante do cantiléver. No modo de força modulada a agulha é varrida com uma pequena oscilação (modulação) vertical ( Z) a qual é significativamente mais rápida do que a taxa de varredura. Quando a agulha é colocada em contato com a amostra, a superfície resiste à oscilação e o cantiléver deflete. Sob a mesma força aplicada, uma área dura sobre a amostra vai deformar menos do que uma área macia, ou seja, superfícies mais duras causam maior resistência à oscilação vertical do cantiléver e consequentemente uma maior deflexão do mesmo. A variação na amplitude de deflexão do cantiléver permite a medida da dureza e/ou viscoelasticidade do material.

Novas técnicas de obtenção de imagem estão sendo desenvolvidas, tais como o modo de força elétrica, força magnética e térmica, fazendo com que novas fronteiras sejam abertas na pesquisa para o estudo de superfície de polímeros.

\section{Estudos de Microscopia de Força Atômica em Polímeros}

O microscópio de força atômica foi aplicado pela primeira vez no estudo de polímeros em 1988, logo depois da sua invenção. Hoje estudos em polímeros abrangem desde a simples visualização da morfologia até o exame mais avançado da estrutura e propriedades do material em escalas nanométricas. Dentre as aplicações de $\mathrm{AFM}^{[8,14]}$ para o estudo de polímeros se destacam: morfologia da superfície, nanoestrutura, empacotamento e conformação das cadeias, estudo tribológico, distribuição de fases por topografia ou por diferença em módulo de elasticidade, nano indentação, estudo de mecanismos de desgaste, porosidade, rugosidade, cristalização expitaxial, mapeamento da distribuição de cargas elétricas, perfil de força de interação química específica, entre outras. A seguir serão apresentados os detalhes de algumas destas aplicações.

As técnicas de varredura de força têm sido utilizadas com sucesso para o estudo de polímeros condutores. Estes polímeros podem ter a sua superfície eletricamente carregada, sendo possível fazer com os SFM o mapeamento de cargas da superfície do material pela varredura de força elétrica. Outra possibilidade que se tem investigado é no estudo de filmes de poli(tereftalato de etileno) - PET recobertos com uma fina camada condutora de polianilina (PANI). Na Figura 5 observa-se uma imagem de AFM mostrando o recobrimento de uma parte de um filme de PET com polianilina. Na Figura 6(a) é mostrado, em um aumento maior, a vista tridimensional do degrau do filme de polianilina, formado na superfície do PET. A espessura do recobrimento pode ser medida fazendo um corte transversal de modo a se obter um perfil do degrau, conforme se observa na Figura 6(b). Além disso, a rugosidade e a morfologia da amostra podem ser analisadas, fazendo uma varredura pelo AFM com maior resolução, como mostra a Figura 7(a), onde se observa a presença de uma morfologia globular da polianilina, cuja análise quantitativa pode ser feita, por exemplo, pela frequência de ocorrência dos glóbulos mostrada na Figura 7(b), através da análise da seção da amostra. As imagens de amostras de PETPANI, que podem ser vistas neste artigo foram obtidas com equipamento TMX 2010 Discoverer, da Topometrix, Santa Clara-CA, USA, o qual está instalado no laboratório de microscopia do Centro de Instrumentação da EMBRAPA, São Carlos-SP.

Utilizando o modo de força modulada do AFM é possível também detectar variações entre os diferentes componentes de um copolímero ou de uma blenda polimérica, assim como a distribuição de fases destes materiais. Em compósitos poliméricos onde a carga de reforço possui maior módulo de elasticidade do que a matriz polimérica o AFM pode distinguir os diferentes módulos de elasticidade dos materiais constituintes mesmo que não haja diferença na topografia do compósito. Isto é feito utilizando-se o modo de contato intermitente, onde a agulha do AFM vibra sobre a amostra e detecta a capacidade do material de absorver a energia do choque com a agulha. Como exem- 


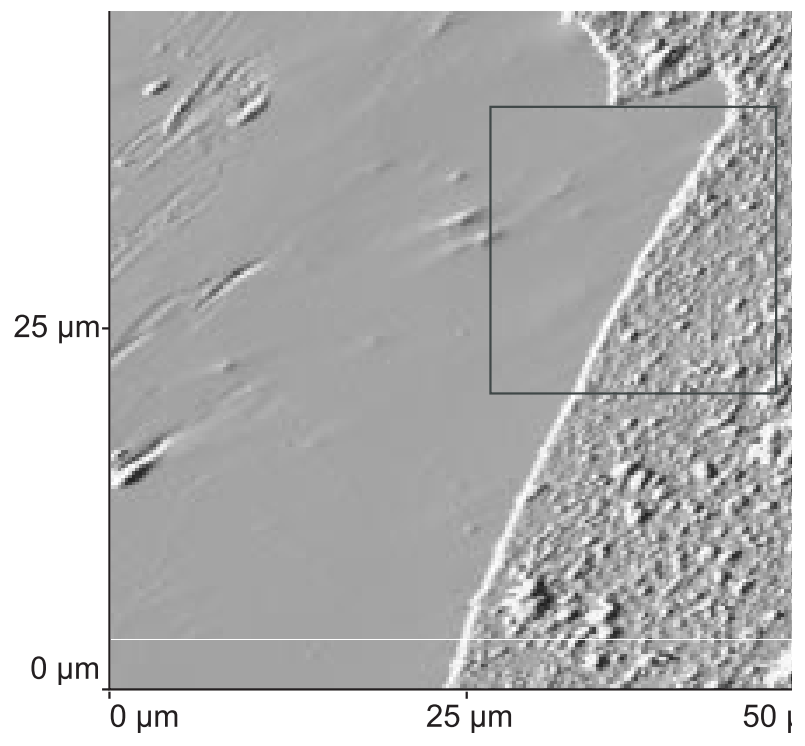

Figura 5. Imagem de AFM pelo modo não-contato mostrando o recobrimento parcial de polianilina sobre o filme de PET. A área de análise da espessura do filme (Fig. 6a) é indicada.

plo, tem-se estudos com composto a base de epoxi reforçado com fibra de carbono e borracha reforçada com fibra de carbono, que apresenta um elevado contraste entre a fibra dura e a borracha flexível.

O AFM pode ser utilizado, por exemplo, no estudo microtribológico (atrito) em filmes comerciais de poli(tereftalato de etileno) - $\mathrm{PET}^{[15]}$ usados como substrato de fita magnética. Neste caso, utilizando-se o modo de força lateral é possível determinar os valores de fricção em microescala e compará-los com os da macroescala. Os resultados de Bhushan ${ }^{[15]}$ demonstram a existência de um efeito de orientação preferencial. Além disso, AFM permitiu a investigação do efeito da adição de cargas minerais à microfricção do PET, assim como estudos de nanoindentação e determinação da nanodureza ao longo da superfície dos filmes, possibilitando a caracterização de propriedades nano mecânicas deste material ${ }^{[15]}$.

Os mecanismos de desgaste de polímeros também podem ser estudados por AFM, assim como a formação e distribuição de tamanho de partículas nanométricas que se desprendem das superfícies com o desgaste. Além disso, tem-se estudado também o efeito de tratamentos de proteção no desgaste de superfícies de, por exemplo, polietileno ${ }^{[16]}$.

AFM também tem sido muito utilizado na análise morfológica da superfície de vários polímeros comerciais. Estudos feitos por $\mathrm{AFM}^{[15]}$ da estrutura cristalina de filmes de HDPE, extrudados a partir de solução, mostraram lamelas de 20-50 nm de espessura e 200-400 nm de comprimento com orientação

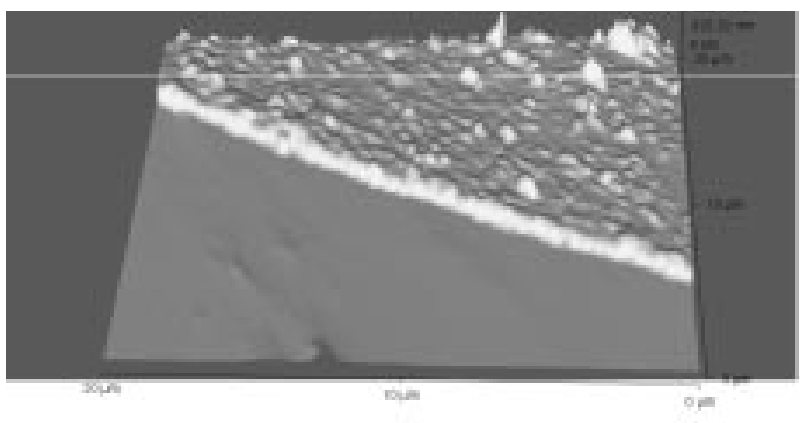

(a)

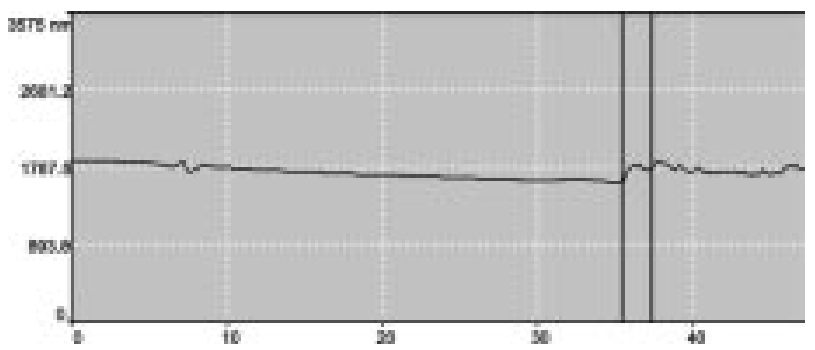

(b)

Figura 6. Imagem de AFM pelo modo não-contato. (a) Vista tridimensional do degrau formado pelo recobrimento parcial de polianilina sobre a superfície do filme de PET, área de $\left(20\right.$ X 20) $\mu \mathrm{m}^{2}$ (indicada na Fig.5). (b) Perfil da topografia demonstrando a diferença do nível entre o filme de PET e a polianilina.

aleatória, enquanto filmes uniaxialmente orientados apresentaram morfologia tipo "shish-kebab". Já para polietileno de baixa densidade (LDPE) e LPDE linear (LLDPE), estudos em filmes extrudados por sopro mostraram uma morfologia na forma de lamelas empilhadas. No caso de filmes de polipropileno (PP), extrudados a partir de solução, foi observada uma morfologia fibrilar ramificada.

$\mathrm{O}$ efeito de diferentes tipos de tratamento em superfícies de polímeros comerciais tais como polipropileno, policarbonato e poliésteres é outra aplicação bastante interessante do AFM. Exemplos são o efeito de tratamento corona na superfície de filmes de PP que demonstrou a formação de grandes glóbulos de $400-500 \mathrm{~nm}^{[17]}$. Para policarbonato a irradiação com íon $\mathrm{Ar}^{+}$em atmosfera de oxigênio foi utilizada para se melhorar sua molhabilidade superficial. Os resultados indicam que a rugosidade superficial pode ser efetivamente aumentada com o tratamento.

Para filmes de polímeros amorfos vítreos como poliestireno e poli(cloreto de vinila) a análise de AFM induziu a erosão da superfície com direção perpendicular ao sentido de varredura. A profundidade desta erosão aumenta com a quantidade de plastificante de ca. $10 \mathrm{~nm}$ (filme não plastificado) para até $100 \mathrm{~nm}$. Assume-se que esta deformação plástica detectada 


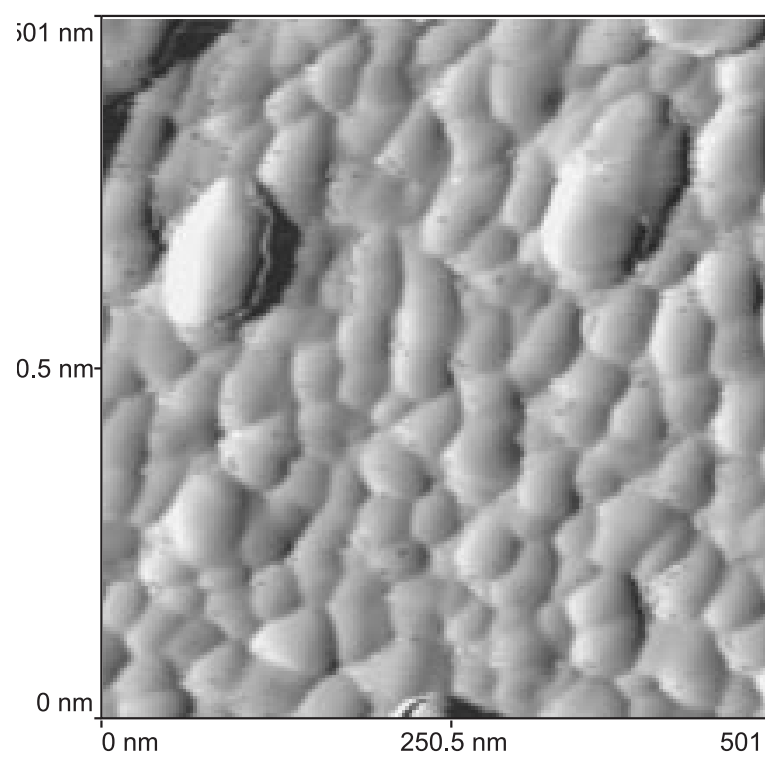

(a)

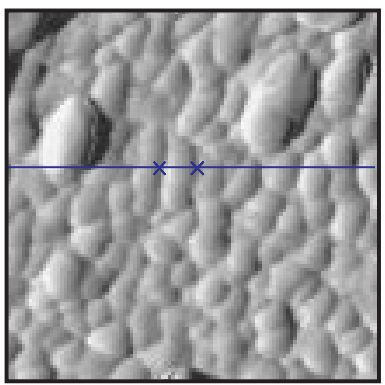

\begin{tabular}{|c|c|c|c|c|c|}
\hline \multicolumn{2}{|c|}{$\begin{array}{l}\text { File Information: } \\
\text { Zmin: } 0.00 \mathrm{~nm}\end{array}$} & \multicolumn{2}{|c|}{ Zmax: $123.82 \mathrm{~nm}$} & Scan Range: $500 \mathrm{~nm}$ & Resolution: $300 \mathrm{x}$ : \\
\hline \multirow[t]{2}{*}{ [ Result: } & & Line 1 & & & \\
\hline & $X(\mathrm{~nm})$ & $\mathrm{Y}(\mathrm{nm})$ & $\mathrm{Z}(\mathrm{nm})$ & & \\
\hline Point1: & 207.5 & 215.4 & 23.32 & & \\
\hline Point2: & 259.1 & 215.4 & 29.92 & & \\
\hline Diff: & 51.6 & 0.0 & 6.60 & & \\
\hline Length: & & $52.041 n$ & & & \\
\hline Pt Angle: & & $7.29^{\circ}$ & & & \\
\hline
\end{tabular}
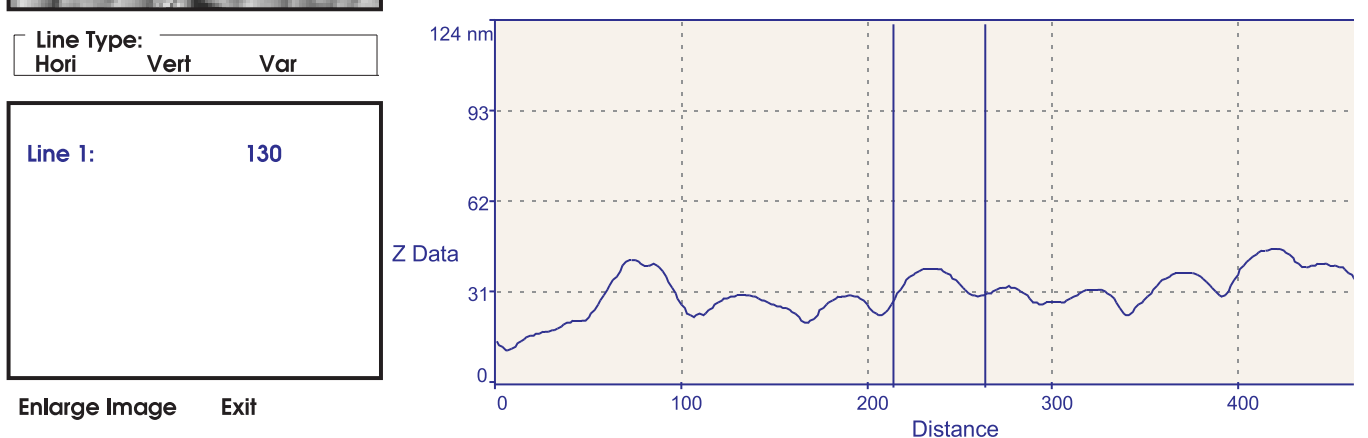

(b) por AFM permitiu a determinação do tamanho de cristais crescidos a $140{ }^{\circ} \mathrm{C}$, sendo a espessura de 10.5 $\pm 1 \mathrm{~nm}$ e a rugosidade na faixa de $0,3-1 \mathrm{~nm}$. O mecanismo de formação de fissuras nestes cristais, em escala nanométrica, e o levantamento estatístico da quantidade de fissuras também foi estudado ${ }^{[19]}$. A cristalização epitaxial de poliolefinas pode ser estudada, revelando-se a morfologia dos polímeros preparados por deposição de multicamadas ${ }^{[20]}$.

O AFM também foi usado para a observação da conformação de partículas de poliestireno que foram espalhadas por um atomizador em superfície de mica a partir de soluções diluídas de poliestireno monodisperso. Observou-se que a morfologia varia com o tipo de solvente utilizado e o tempo de secagem. Além disso, a morfologia pode ser orientada pela interação da agulha

Figura 7. (a) Imagem de AFM pelo modo não-contato do filme de polianilina depositado sobre o filme de PET; (b) Perfil de uma linha traçada sobre a superfície, ilustrando a medida da largura de um glóbulo da polianilina.

na superfície destes polímeros, mesmo abaixo da sua temperatura de transição vítrea $(\mathrm{Tg})$, se deva ao fato da superfície destes materiais possuir uma camada fina cuja Tg esteja abaixo da $\mathrm{Tg}$ do seu volume todo.

Outra possibilidade de aplicação do AFM é no estudo da porosidade de membranas poliméricas, pois esta técnica permite revelar variações morfológicas dos poros e esclarecer diferenças nas propriedades de transporte das membranas, quando impregnadas com cristais líquido ${ }^{[18]}$, por exemplo.

$\mathrm{O}$ estudo de cristais únicos de PP sindiotático feito com as partículas de poliestireno ${ }^{[21]}$. Usando-se o AFM modificado para o modo de força modulada ${ }^{[22]}$, o mesmo pode ser utilizado para o estudo da elasticidade local de poliestireno, na escala desejada, até nível nanométrico. Goudy ${ }^{[23]}$ estudou também a topografia de filmes finos de látex de poliestireno depositados sobre mica em função do tamanho das partículas, do tempo de tratamento térmico e do envelhecimento. Os filmes obtidos se apresentaram como policristalinos, consistindo de domínios hexagonais de longo alcance com partículas bastante empacotadas, sendo que os defeitos 

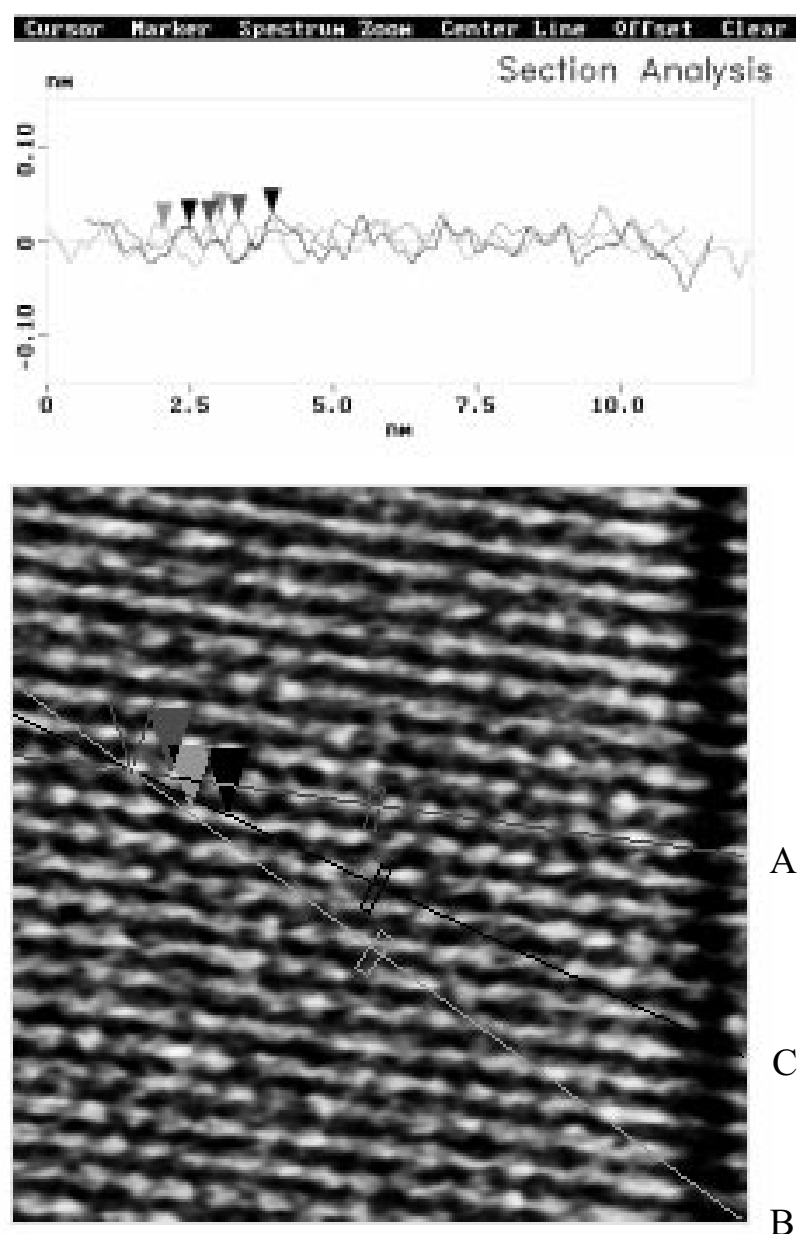

Figura 8. Imagem de AFM pelo modo contato da superfície da mica em

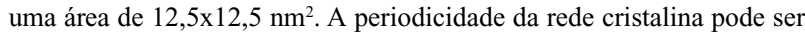
observada na imagem e no perfil das retas (gráfico acima). Os parâmetros A, B e C são as distâncias entre dois átomos mais próximos nas direções das 3 retas indicadas.

dos cristais diminuíram com o aumento da monodispersividade das partículas. Outra aplicação interessante do AFM é para se medir a força de adesão em adesivos de, por exemplo, látex de poliestireno preparados a partir da dispersão de partículas por vários métodos em multicamadas. A força de interação da agulha com o adesivo é analisada medindo-se o amortecimento da vibração do cantiléver durante a varredura da amostra pelo método de contato intermitente ${ }^{[24]}$.

O fenômeno de ordenação de copolímeros em bloco de estireno-butadieno-estireno (SBS) também pode ser estudado por AFM. Vandijk ${ }^{[25]}$ observou, em SBS comercial com morfologia cilíndrica, que a orientação dos cilindros de poliestireno dependem da espessura do filme. Para filmes mais espessos do que duas distâncias de repetição, a orientação é perpendicular às superfícies. Orientação paralela só é possível para certas condições de preparação e determinadas espessuras do filme.
O potencial do AFM chega efetivamente à obtenção de imagens em nível atômico. A Figura 8 apresenta a análise de uma imagem para uma amostra de mica muscovita, mostrando resolução em nível atômico. $\mathrm{O}$ cálculo das distâncias atômicas em diferentes direções, parâmetros A, B, e C indicados na Figura 8, servem para a determinação da precisão desta técnica e calibração do equipamento. Para o presente caso, os seguintes valores experimentais (literatura) foram obtidos respectivamente para A, B e C: $5,08(5,19)$ Angstron, 9,9 $(9,0)$ Angstron e $14,4(13,7)$ Angstron. A análise em escala atômica molecular tem sido obtida para vários outros materiais, dentre os quais se destacam $\mathrm{MoS}_{2}, \mathrm{TaS}_{2}$ e $\mathrm{Wte}_{2}{ }^{[26]}$. Esta é sem dúvida alguma, uma possibilidade de aplicação de extrema importância para a pesquisa em materiais, onde a ciência parece atingir os extremos do conhecimento e da interdisciplinaridade.

Estes são apenas alguns exemplos que foram selecionados para mostrar a potencialidade da técnica de AFM para o estudo de polímeros. Os trabalhos envolvendo estudos de AFM de polímeros têm crescido significativamente dia a dia. Estes estudam a influência de diferentes processos nas características morfológicas e estruturais superficial de uma grande variedade de polímeros ${ }^{[27-37]}$ tais como poli (tereftalato de etileno), policarbonato, náilon, poliéster, poliuretanas, polímeros acrílicos, ABS, poliestireno, polipropileno, polietileno, proteínas, fibras vegetais, polímeros condutores, entre outros.

\section{Referências Bibliográficas}

1. Binnig, G.; Rohrer, H.; Gerber, Ch.; Weibel, E. Surfaces studies by scanning tunneling microscopy. Phys. Rev. Let., v.49, n.1, p.57-61, (1982).

2. Binnig, G.; Quate, C.F.; Gerber, Ch. Atomic force microscope. Phys. Rev. Let., v.56, n.9, p.930933, (1986).

3. Bottomley, L.A.; Coury, J.E.; First, P.N.; Scann. Probe Microsc. Analyt. Chem. v.68, p.185R230R, n.12, (1996).

4. Meyer, E.; Atomic force microscopy. Prog. in Surf. Sci. v.41, p.3-49, (1992).

5. Digital Instruments, NanoScope Command Reference Manual, Santa Barbara - CA. 
6. Park Scientific Instruments, A practical guide to scanning probe microscopy, p. 74 (1996).

7. Israelachivili, J.; Intermol. and Surf. Forces, Academic Press, San Diego, CA, p.312, (1992).

8. Wiesendanger, R.; Scanning Probe Microscopy and Spectroscopy. Cambridge University Press, Cambridge, (1994).

9. Frommer, J.; Scanning probe microscopy of organics, an update. Thin Solids Films. v.273, p.112-115, (1996).

10. Binning, G.; Fuchs, H.; Gerber, Ch.; Rohrer, H.; Stoli, E.; Tosatti, E.; Europhys. Lett. v.1, p.31, (1986).

11. Binggeli, M.; Mate, C.M.; Influence of water vapor on nanotribology studied by friction force microscopy. J.Vac.Sci.Technol.B, v.13, n.3, p.1312-1315, (1995).

12. Overney, R.; Meyer, E.; Tribological investigations using friction force microscopy. MRS Bull., p.26-34, (1993).

13. Bhushan, B.; ed. Handbook of Micro/ Nanotribology. CRC Publishers, Boca Raton, FL, (1995).

14. Frommer, J.; Scanning tunneling microscopy and atomic force microscopy in Organic chemistry. Angew. Chem. Int. Ed. Engl., v.31, p.12981328, (1992).

15. Bhushan, B.; Koinkar, V.N.; Microtribology of Pet Polymeric Films, Tribol. Trans., Vol 38, n. 1, pp 119-127, (1995).

16. Mosleh, M. Suh, N.P., Wear Particles of Polyethylene in Biological-Systems, Tribol. Trans., Vol 39, n. 4, pp 843-848, (1996).

17. Vancso, G.J.; Allston, T.D.; Chun, I.; Johansson, L.S.; Liu, G.B.; Smith, P.F.; SurfaceMorphology of Polymer-Films Imaged by Atomic-Force Microscopy, Int. J. of Polym. Anal. and Characteriz., Vol 3, n. 1, pp 89-105, (1996).

18. Vandenberg, R.; Schulze, D.; Boltwesterhoff, J.A.; Dejong, F.; Reinhoudt, D.N.; Velinova, D.; Buitenhuis, L.; Influence of Membrane Microstructure on the Diffusion Barrier of Supported Liquid-Crystalline Membranes, J. of Phys. Chem., Vol 99, n. 19, pp 7760-7765, (1995).

19. Tsukruk, V.V.; Reneker, D.H.; SurfaceMorphology of Syndiotactic Polypropylene Single-Crystals Observed by Atomic-Force Microscopy, Macromolecules, Vol 28, n. 5, pp 1370-1376, (1995).

20. Katzenberg, F.; Loos, J.; Petermann, J.; Mcmaster, T.; Miles, M.; A Cross-Sectional Preparation Method for TEM and AFM Investigations on Layered Polymer Interfaces, Polym. Bull., Vol 35, n. 1-2, pp 195-200, (1995).

21. Qian, R.Y.; Shen, J.S.; Bei, N.J.; Bai, C.L.; Zhu, C. F.; Wang, X.W.; Morphological Observations of Single-Chain Glassy Polystyrene by Means of Tapping Mode Atomic-Force Microscopy, Macromol. Chem. and Phys., Vol 197, n. 7, pp 2165-2174, (1996).

22. Nie, H.Y.; Motomatsu, M.; Mizutani, W.; Tokumoto, H.; Local Elasticity Measurement on Polymers Using Atomic-Force Microscopy, Thin Solid Films, Vol 273, n. 1-2, pp 143-148, (1996).

23. Goudy, A.; Gee, M.L.; Biggs, S.; Underwood, S.; Atomic-Force Microscopy Study of Polystyrene Latex Film Morphology - Effects of Aging and Annealing, Langmuir, Vol 11, n. 11, pp 44544459, (1995).

24. Anczykowski, B.; Chi, L.F.; Fuchs, H.; AtomicForce Microscopy Investigations on Polymer Latex Films, Surf. and Interf. Anal., Vol 23, n. 6, pp 416-425, (1995).

25. Vandijk, M.A.; Vandenborg, R.; Ordering Phenomena in Thin Block-Copolymer Films Studied Using Atomic-Force Microscopy, Macromolecules, Vol 28, n. 20, pp 6773-6778, (1995)

26. Albrecht, T. R.; Advances in Atomic Force Microscopy and Scanning Tunneling Microscopy. Stanford: Stanford University,. PhD Thesis, (1989).

27. Thomson, N. H.; Fritz, M.; Radmacher, M.; Cleveland, J. P.; Schmidt, Ch. F.; Hansma, P. K.; Protein Tracking and Detection of Protein Motion using Atomic Force Microscopy. Biophys. J., Vol. 70, pp. 2421-2431, (1996). 
28. Herrmann, P.S.P.; Mattoso, L.H.C.; Frommer, J.E.; Colnago, L.A.; Uso da Microscopia de Força Atômica para Estudos de Morfologia de Fibra Vegetal. In: Simpósio Nacional de Instrumentação Agropecuária, 1., São CarlosSP, nov. 1996 Anais... São Carlos: EMBRAPACNPDIA, 1996. (no prelo).

29. Riul J.R.; A.; Mattoso, L.H.C.; Telles, G.D.; Herrmann, P.S.P.; Colnago, L.A.; Parizotto, N.A.; Baranauska, V.; Faria, R.M.; Oliveira Jr. O.N.; Characterization of Langmuir-Blodgett films of parent polyaniline. Thin Solid Films, v. 284-285, p.177-180, (1996).

30. Magonov, S.N.; Whangbo, M.H.; Polymers, Chap 13, In: Surface Analysis with STM and AFM, VCH pub, Fed. Repub. Germany, Weinhem, p. 277, (1996).

31. Xu, M.X.; Liu, W.G.; Wang, C.L.; Gao, Z. X.; Yao, K.D.; Surface Crystalline Characteristics of Polyurethane Investigated by Atomic-Force Microscopy, J. of Appl. Polym. Sci. Vol 61, p.2225-2228 (1996).

32. Lian,Y.; Leu, K. W.; Liao, S. L.; Tsai, V. M.; Effects of Surface Treatments and Deposition Conditions on the Adhesion of Silicon Dioxide Thin-Filn on Polyrnethylmethacrylate, Surface \& Coatings Technology, vol 71, Iss 2, pp 142150, (1995).

33. Brocherieux A.; Dessaux O.; Goudmand P.; Gebgembre L.; Brunel M.; Lazzaroni R.;
Characterization of Nickel Films Deposited by Cold Remote Nitrogen Plasma on Acrylonitrilebutadiene-styrene Copolymer, Applied Surface Science vol 90, 1ss i, pp 47-58, (1995).

34. Baty, A. M.; Suci, P. A.; Tyler, B. J; Geesey, G. G.; Investigation of Mussel Adhesive Protein Adsorption on Polystyrene and Poly(Octadecyl Methacrylate) Using Angle Dependent XPS, ATR-FTIR and AFM, J. of Colloid and Interface Science, vol 177, lss 2, pp 307-315, (1996).

35. Bu, Z.Z.; Yoon, Y.; Ho, R. M.; Zhou, W.S.; Jangchud, I.; Eby, R.K.; Cheng, S.Z.D.; Hsieh, E.T.; Johnson, T.W.; Geerts, R.G.; Palackal, S.J.; Hawley, G.R.; Welch, M.B.; Crystallization, Melting, and Morphology of Syndiotactic Polypropylene Fractions .3. Lamellar SingleCrystals and Chain Folding, Macromolecules, vol 29, 1ss 20, pp 6575-6581, (1996).

36. Schonherr, H.; Vancso, G.B.; Argon, A.S.; The Structure of Highly Textured Quasi-SingleCrystalhne High-Density Polyethylene Probed by Atomic-Force Microscopy and Small-Angle X-Ray-Scattering, Polymer, vol 36, iss i i, pp 2115-2121, (1995).

37. Herrmann, P.S.P.; Colnago, L.A.; Mattoso, L.H.C.; Cruvinel, P.E.; Frommer, J.E. Analysis of spatial variability of lyosozyme thin film by AFM. In: -P gengemibre-1, Meeting of the Brazilian Society for Electron Microscopy, 16., 1997, Caxambu, MG. Acta Microscopica, v.6, suppl. A, p. 290-291, (1997). 